\title{
Early Contractor and Facility Management Team Involvement in the BIM Environment
}

\author{
Hao Wang ${ }^{1 *}$, Xianhai Meng ${ }^{1}$, Patrick J. McGetrick ${ }^{1}$ \\ ${ }^{1}$ School of Natural and Built Environment, Queen's University Belfast, David Keir Building, Stranmillis Road, Belfast, BT9 5AG, UK \\ ${ }^{*}$ Corresponding author, e-mail: hwang17@qub.ac.uk
}

Received: 15 June 2018, Accepted: 21 June 2018, Published online: 29 June 2018

\begin{abstract}
Knowledge is the resource that contributes the most to an organisation's competitiveness. Construction projects usually introduce project teams from different disciplines. Hence, knowledge in projects is complex and difficult to manage. To efficiently manage knowledge in projects, various strategies and tools have been applied over the years to support knowledge management (KM). Building information modelling (BIM) is a technology that has recently gained a lot of attention in the construction industry. The main feature of BIM is object-oriented and parametric modelling with the functions of dynamic visualisation, life cycle simulation, early analysis, coordination and collaborative working. Many studies have explored the functions of BIM mainly at the information level. However, only a few studies have considered the management of knowledge in a BIM environment. To fill this knowledge gap, this study explored the potential and expectation of a BIM-based system for early collaboration among contractor, facility management (FM) and design teams in the design stage. This study chose semi-structured interview as the main method to collect qualitative information. A total of 30 experts working in the construction industry were interviewed. On the basis of the analysis results of the collected information, a discussion was presented on how BIM can facilitate KM activities and relieve KM challenges. Therefore, the discussion focused on the requirements and expectations of the integrated KM system in a BIM environment that can facilitate the early involvement of construction contractors and the FM team into the design stage. This study also provides a new research direction for the transformation of research focus from BIM to building knowledge modelling. This paper is the revised version of the paper that has been published in the proceedings of the Creative Construction Conference 2018 (Wang et al., 2018).
\end{abstract}

\section{Keywords}

building information modelling, knowledge management, construction project management, collaboration

\section{Introduction}

Knowledge is the most critical resource for any organisation to maintain its competitiveness, and organisations in the construction industry are no exception (Ofek and Sarvary, 2002). Studies define knowledge from different perspectives. The widely accepted way to define knowledge is to distinguish data, information and knowledge. According to Dretske (1983), data are raw and unstructured symbols, whereas information is organised and processed data with a meaning. Quigley and Debons (1999) further distinguished information and knowledge by defining information as a source applied to answer 'when', 'where', 'who' and 'what' questions, whereas knowledge is mainly used to answer 'how' and 'why' questions. Accordingly, data, information and knowledge should be arranged in three different hierarchies, in which data are at the bottom and knowledge is at the top.

Construction is recognised as a knowledge-intensive industry. Construction projects can greatly benefit from knowledge, such as avoidance of time and cost overrun, prevention of health and safety accidents and improvement of project lifecycle performance (Anumba et al., 2008). Accordingly, knowledge management (KM) has become the most important task in construction processes. However, with the increasing complexity of today's construction projects, coupled with their temporary and fragmentary nature, $\mathrm{KM}$ in construction projects has become increasingly challenging (Prencipe and Tell, 2001; Sydow et al., 2004). 
To adapt to the increasing difficulty of KM in construction projects, various information technology (IT) tools and IT-based techniques have been widely developed and applied in construction projects to aid KM. These tools and techniques have been involved in various KM activities, namely, knowledge capture, retention, sharing and reuse. Meanwhile, IT-supported KM is used in each stage of a project, namely, design (Soibelman et al., 2003), construction (Kivrak et al., 2008) and operation and maintenance (O\&M) (Fong and Wong, 2009). Moreover, because the emphasis is placed on building sustainability, the KM has shifted its focus from a single stage of a project to the whole project's lifecycle (Tserng et al., 2009). Although ITs have been used to support the KM in construction projects, some aspects still need to be further improved, such as the collaborative and proactive KM.

Building information modelling (BIM) is an emerging technology and is extensively used in the AEC industry. $\mathrm{BIM}$ is a process that integrates geometric and non-geometric information of a project to facilitate information exchange between project teams throughout the project lifecycle (Eastman et al., 2011). Existing studies on BIM can be classified into two main aspects, namely, technical related (e.g. clash detections, energy simulations, time and cost estimations and data interoperability) and process related (e.g. collaboration, information sharing, BIM adoption and BIM-based procurements).

However, the abovementioned BIM-related studies have mainly focused on the information level rather than the knowledge level. At present, only a few studies have explored the KM facilitated by BIM. In addition, no study has systematically explored the BIM potential for KM and has figured out the requirements and expectations of BIM-based KM for collaboration, especially during the early design stage.

Therefore, this study aims to explore how the knowledge of construction contractors and the FM team can be involved in the early design stage in a BIM environment. To fill this knowledge gap, this study tries to answer the following questions. (1) How is knowledge managed in current construction projects? (2) How can the current projects involve construction contractors and the FM team in the design stage? (3) What is the potential of BIM for KM? (4) What are the requirements and expectations of the BIM-based KM system that can be used for the early involvement of construction contractors and the FM team?

\section{Literature review}

\section{$2.1 \mathrm{KM}$ in construction}

Construction is a knowledge-based industry. Due to the temporary nature of construction projects, a formal mechanism to capture, retain, share and store the knowledge is needed (Prencipe and Tell, 2001; Sydow et al., 2004). Furthermore, losing knowledge at the end of a project is very easy as professionals are usually transferred immediately to the next project with the lessons learned existing in their mind when they have completed their work. Accordingly, construction projects can hardly transfer the knowledge to a permanent part of an organisation (Carrillo et al., 2004).

In addition, the content and context of KM are changing throughout the project lifecycle. For example, the main purpose of $\mathrm{KM}$ in the design phase is to promote design innovation, improve constructability and satisfy client requirements, whereas in the construction phase, KM strategies should deal with issues about construction materials, construction planning, methods and local practices (Song et al., 2009). However, KM in the O\&M phase aims to improve the building performance to meet the requirements of the building user (Meng, 2013). Therefore, the effective and efficient management of knowledge throughout the project lifecycle is crucial and challenging. As construction projects become increasingly complex, various disciplinary teams are required to collaborate in projects. However, due to different educational backgrounds, work experiences and tasks, mutual understanding between them is lacking. As a result, knowledge sharing between teams can lead to misunderstanding and ambiguity. Knowledge transfer between different disciplinary teams can be a difficult task (Kamara et al., 2002).

\subsection{Generic IT-supported KM in construction}

Many KM-related techniques have been used in construction projects, including brainstorming, communities of practice, face-to-face interactions, trainings and post-project reviews (Anumba et al., 2008). However, as construction projects become increasingly complex, high requirements for KM have been put forward. Consequently, sole reliance on people to manage knowledge is difficult. To alleviate this difficulty, many IT tools have been applied to each KM activity in construction projects, namely, knowledge capture, sharing, storage and reuse as exemplified in existing studies.

IT-based knowledge capture, which has developed from audio diaries (Hari et al., 2005) to Web 2.0 applications 
(Kivrak et al., 2008; Udeaja et al., 2008), has gained a lot of research attention. For example, Soibelman et al. (2003) developed a design review checking system that captures knowledge generated from a review process and transfers such knowledge to a permanent part of an organisation. However, knowledge in engineering projects is experience based and tacit, thereby resulting in difficulties in knowledge capture and recording (Anumba et al., 2008). Although existing studies have involved the management of tacit knowledge, most of them facilitate the exchange of tacit knowledge by enhancing interaction. For example, Lin and Lee (2012) developed a KM system that integrates the communities of practice to improve the tacit knowledge capture and sharing. However, the improvement of interaction can only support the temporary communication of tacit knowledge. Only a limited number of previous studies have explored the retention and storage of tacit knowledge. Consequently, the reusability of tacit knowledge is still a problem that needs to be solved. As mentioned in Section 1, the nature of construction projects is temporary and fragmentary. Therefore, the knowledge generated during projects should be captured and transferred to the organisation for reuse. However, this work usually happens at the end of a project, during which some professionals have already moved on to the next project. To alleviate this problem, Udeaja et al. (2008) developed a web-based system to achieve the proposed concept of 'live' capture and reuse of knowledge.

ITs are also used to facilitate knowledge sharing in construction projects. Most of these KM systems aim to improve their communication functions to aid the knowledge-sharing process. Web-based technologies are also widely used for knowledge sharing. For example, Lin et al. (2006) integrated a web tool with knowledge map to facilitate knowledge sharing in construction. In addition, Le et al. (2014) developed a social network-based KM system to support the sharing of health and safety-related knowledge. However, the combination of web technologies with KM can only facilitate explicit knowledge sharing, whereas its contribution in terms of tacit knowledge sharing is limited (Dave and Koskela, 2009). Although some KM techniques that can improve interaction are integrated into web tools to support the tacit knowledge sharing, such as communities of practice (Lin and Lee, 2012), the sharing of tacit knowledge between different disciplines is still a challenge.

The knowledge reuse process should be divided into two steps, namely, knowledge retrieval and adaptation. Many existing studies have explored how ITs can facilitate knowledge retrieval, and the most common retrieval scheme includes keywords (Lin et al., 2006), ontologies (Park et al., 2013a) and data/text mining (Lee et al., 2008; Ur-Rahman and Harding, 2012). Construction projects require collaboration between different disciplinary teams. Different disciplinary teams have different educational backgrounds and conduct different tasks, thereby resulting in their use of different terms to describe knowledge. However, existing studies on IT-based knowledge retrieval fail to consider knowledge retrieval under a collaborative environment. Knowledge adaptation refers to the process of adjusting the retrieved solutions to adapt to the currently encountered problems. Existing studies on IT-based KM ignore the process of knowledge adaptation when reusing the knowledge.

Databases are extensively used in knowledge storage, which requires a predefined classification structure for knowledge index. This process mainly relies on the manual classification that is labour intensive and subjective. In addition, some knowledge may be to classify into a certain category, or they may belong to multiple categories at the same time. To overcome this problem, an automatic knowledge classifier is developed and combined with the database developed by Chi et al. (2014).

\subsection{BIM-based KM}

At this stage, only a small number of studies have recognised the potential of BIM that can be used to facilitate KM. Although the relevant studies are just emerging, they have been involved in various aspects of KM, namely, knowledge capture, sharing, storage and retrieval.

At present, three main methods are used to capture knowledge in the BIM environment. The first method is to capture and retain the knowledge through predefined customised parameters in the BIM model (Motawa and Almarshad, 2013; Deshpande et al., 2014). This method is based on the parametric modelling and object-oriented nature of BIM. The second method is the knowledge capture method, in which the application programming interface provided by software vendors is applied to capture and convey data to BIM models through external applications (Wang and Leite, 2016). The last method is to combine BIM with a professional knowledge capture tool (Fruchter et al., 2009; Motawa et al., 2014). In terms of the knowledge capture through the BIM parameters, BIM allows users to create customised parameters to add the knowledge related to the building objects and projects (Motawa and Almarshad, 2013). In addition, in the BIM-based 
KM system developed by Deshpande et al. (2014), different user-defined parameters, such as lessons learned and involved professionals, are used to capture knowledge. However, although existing studies have recognised that customised parameters of BIM can be used to support knowledge capture, no study has focused on the development of a common structure of the parameters that suit the collaboration between the different disciplines. Notably, studies on BIM-based knowledge capture do not discuss the capture of tacit knowledge.

Knowledge sharing supported by BIM is mainly based on the integration of BIM and knowledge-sharing tools, such as web tools (Ho et al., 2013) and desktop applications (Grover and Froese, 2016). BIM combined with webbased applications can use accessibility, search capability and social interaction of web-based technologies and maximise the 3D description and parametric modelling features of BIM. For example, Ho et al. (2013) developed a BIM-based web application to share knowledge in a text format. The knowledge in text format is sometimes difficult to be understood; hence, this system applies $3 \mathrm{D}$ visualisation of BIM to help understand the related knowledge. As a result, knowledge can be easily shared, especially among different disciplines.

BIM as a centralised platform allows the models developed by different project teams to be integrated into a single model, which makes design coordination between different teams easier (Eastman et al., 2011). Compared with the traditional design coordination that only concerns the geometric relationship between the building objects, BIM coordination further considers the semantic relationship between building objects. This is because the BIM model contains building objects and their related parameters. Accordingly, the coordinated BIM model can be viewed as an intelligent collaborative platform that can provide a shared and information-rich context for design teams to collaboratively discuss the problems existing in the integrated model based on their knowledge (Kim and Grobler, 2009).

At present, only limited studies consider knowledge reuse under a BIM environment, and most of them consider knowledge retrieval. For example, Park et al. (2013b) and Ding et al. (2016) applied ontologies to help represent knowledge, by which the knowledge is easily retrieved under the BIM environment. To facilitate the knowledge that can be retrieved by people who are not familiar with a specific knowledge domain, Gómez-Romero et al. (2015) combined fuzzy description logics with ontology in the
BIM-based system to improve the knowledge retrieval results, in which the retrieval mechanism is not either 'true or false' but relatively holds the truth. In addition, case-based reasoning (CBR) has been involved in the BIM system for knowledge storage and retrieval (Motawa and Almarshad, 2013; Motawa and Almarshad, 2015). Thus far, knowledge adaptation in the BIM environment has not been explored by studies. Table 1 summarises the current studies on the BIM-based KM.

\subsection{Early involvement of knowledge of construction and $F M$ into the design stage}

Early contractor involvement (ECI) is proposed by the UK Highways Agency and aims to engage contractors earlier than normal to help with the design (Samuel and Ron, 2016). ECI can strengthen the connection between the contractors and the design team, which can provide contractors an opportunity to express their ideas in the early design stage based on their experience and knowledge. Because the contractors have rich experience and knowledge about the selection of materials and construction methods and the estimation of cost and time, construction projects can gain a lot of benefits from ECI.

According to Jensen (2009), the FM team is a group of people responsible for the operational costs, O\&M, energy consumption and future adaptation and development of a facility. In addition, the FM team usually has a connection with end users and knows the requirements of the building users to support their business objectives. Therefore, if the FM team is involved in the early design stage (EFMI), the project will gain many benefits. Table 2 lists the benefits of ECI and EFMI in detail.

In addition to the benefits gained from ECI and EFMI, barriers and challenges have also been identified by studies. The six barriers to ECI are as follows: responsibility allocation (Jergeas and Van der Put, 2001; Samuel and Ron, 2016), reluctance to change (Jergeas and Van der Put, 2001; Song et al., 2009; Love et al., 2014), lack of understanding of benefits (Song et al., 2009; Eadie et al., 2012), lack of mutual trust and respect (Jergeas and Van der Put, 2001), lack of competitiveness (Motiar and Aminu, 2012) and lack of technical support (Gil et al., 2001; Jergeas and Van der Put, 2001). Previous studies have also identified three barriers to EFMI: lack of understanding of benefits (Dunston and Williamson, 1999; Meng, 2013), lack of mutual knowledge (Jensen, 2009; Meng, 2013) and lack of technical support (Bröchner, 2003; Jensen, 2009). 
Table 1 Summary of current studies on BIM-based KM

\begin{tabular}{|c|c|c|}
\hline Phase of project & References & KM aspect \\
\hline \multirow{5}{*}{ Design phase } & Fruchter et al. (2009) & Knowledge capture \\
\hline & Kim and Grobler (2009) & Knowledge representation \\
\hline & Nguyen and Toroghi (2013) & Knowledge representation \\
\hline & Wang and Leite (2016) & Knowledge capture \\
\hline & Park et al. (2013a) & Proactive KM and knowledge retrieval \\
\hline \multirow{3}{*}{ Construction phase } & Jan et al. (2013) & Knowledge capture, sharing, storage and reuse \\
\hline & Ho et al. (2013) & Knowledge capture, sharing, storage and reuse \\
\hline & Lin (2014) & Knowledge capture, sharing, reuse, storage and representation \\
\hline Design and construction phases & Deshpande et al. (2014) & Knowledge capture and storage \\
\hline \multirow{5}{*}{ FM phase } & Liu and Issa (2012) & Knowledge sharing \\
\hline & Motawa and Almarshad (2013) & Knowledge capture and reuse \\
\hline & Charlesraj (2014) & Knowledge representation \\
\hline & Motamedi et al. (2014) & Knowledge visualisation and representation \\
\hline & Motawa and Almarshad (2015). & Knowledge capture and retrieval \\
\hline \multirow{3}{*}{ Throughout the project lifecycle } & Konukcu and Koseoglu (2012) & Knowledge sharing \\
\hline & Kivits and Furneaux (2013) & Collaborative and proactive KM \\
\hline & Liu et al. (2013) & Knowledge capture, sharing and reuse \\
\hline Others & Meadati and Irizarry (2010) & Knowledge capture and storage \\
\hline
\end{tabular}

Table 2 Benefits of ECI and EFMI

\begin{tabular}{|c|c|}
\hline Benefits & References \\
\hline \multicolumn{2}{|l|}{ Benefits of ECI } \\
\hline Improved constructability & Gil et al., 2000; Song et al., 2009; Motiar and Aminu, 2012; Love et al., 2014 \\
\hline Enhanced relationship & Arditi et al., 2002; Kadefors, 2004; Motiar and Aminu, 2012 \\
\hline Innovation & Gil et al., 2000; Van Valkenburg et al., 2008; Motiar and Aminu, 2012 \\
\hline Informed decision-making & Gil et al., 2000; Song et al., 2009; Samuel and Ron, 2016 \\
\hline Avoidance of risk & $\begin{array}{l}\text { Gil et al., 2000; Van Valkenburg et al., 2008; Song et al., 2009; Eadie et al., 2012; Motiar and } \\
\text { Aminu, 2012; Love et al., 2014; Meng, 2014; Samuel and Ron, } 2016\end{array}$ \\
\hline Satisfaction of clients & Samuel and Ron, 2016 \\
\hline \multicolumn{2}{|l|}{ Benefits of EFMI } \\
\hline Operability and maintainability & Mohammed and Hassanain, 2010; Meng, 2013 \\
\hline Improved O\&M of future projects & Mohammed and Hassanain, 2010 \\
\hline Selection of equipment & Mohammed and Hassanain, 2010; Wang et al., 2013 \\
\hline Satisfaction of clients/end users & Mohammed and Hassanain, 2010; Wang et al., 2013 \\
\hline Reduction of lifecycle cost & Mohammed and Hassanain, 2010; Wang et al., 2013 \\
\hline Adaptability for future needs & Jensen, 2009; Mohammed and Hassanain, 2010 \\
\hline
\end{tabular}

\section{Research methodology}

To collect detailed information rather than a general and broad information, this study adopted semi-structured interviews as the main research method. A total of 30 interviewees were selected from $30 \mathrm{UK}$ and Irish construction companies that differed in size, task and location. The selection of interviewees was based on a purposeful sampling strategy that is mainly applied to identify people who have experienced a certain phenomenon of interest (Patton, 1990). Interviewees are working in different organisation types, namely, design, construction, FM, consulting company and client. The number of interviews was chosen using the information saturation criterion, where no new information is generated from additional interviews over a particular interviewee sample size (Patton, 1990). 
The predesigned interview paradigm was developed and revised based on the literature review and four pilot interviews. The interview process included three parts. Firstly, interviewees were asked to provide their personal information and their organisation information to confirm if they are suitable for the qualitative research. Secondly, current KM strategies in the interviewees' companies were explored, which includes KM tools and techniques, KM activities (i.e. knowledge capture, retention, sharing and reuse) and BIM's potential for KM. Lastly, interviewees were asked to describe how the contractors and the FM team were involved in the design stage of a project. They were also asked to provide their perspectives on how BIM can aid the early engagement process. Moreover, the interviewees were asked to specify their needs for and expectations of a proposed BIM-based KM system to assist the ECI and EFMI.

The findings of this study were derived from content analysis of the collected information from the interviews. Content analysis is an effective way to code interview information and generate themes from it (Patton, 1990). The interviewees were conducted face to face or through Skype video calls. Each interview lasted for approximately one hour. The interview process was audio recorded, transcribed and imported to NVivo 11 for content analysis.

\section{Findings and discussion}

\subsection{ECI and EFMI in the current construction industry}

The interview results indicate that the interviewees agree that the contractors should be involved before the start of the design drawing rather than during the design process. Interviewees from the design disciplines explained that a client occasionally asks the design team to present their ongoing works, and the contractor is asked to conduct value engineering for the client. Consequently, a few design schemes should be changed, thereby increasing the design team's workloads. Hence, the design team is reluctant to show their design to the contractor to avoid the additional work caused by redesigning. This finding is consistent with the study result of Song et al. (2009). Moreover, a few interviewees suggested that subcontractors should be considered during the ECI process because they have substantial knowledge of technical details, and their knowledge is considerably targeted to such specific aspects. Gil et al. (2000) and Gil et al. (2001) also emphasised the importance of subcontractors in the early design stage. One of the interviewees indicated that several subcontractors had their own design teams. Hence, they will conduct the design work based on the general requirements and description of the project design team. If they need to further discuss with the project design team, then they can ask the main contractors to hold a meeting for them. Furthermore, a few interviewees mentioned that the contractors are invited to participate in the design coordination meeting, which can also be considered a form of ECI.

Different from ECI, some interviewees believed that the FM team should be involved during the whole design process. These interviewees believed that people working in FM discipline may lack geometric thinking and design-related knowledge and the FM people can hardly visualise the design intentions in their minds. Accordingly, the communication of knowledge between the design and FM teams is inefficient without the design drawings and sometimes leads to misunderstanding. By contrast, a small number of interviewees believed that relying excessively on visualisation, such as design drawings, would reduce the efficiency of knowledge exchange between the design and FM teams. The FM team may need extra time to understand the design drawing before they could give their advice to the design teams.

In addition, the interviewees described the issues they encountered in implementing ECI and EFMI. Through the analysis, these issues can be classified into two categories, namely, cultural and technical issues, which are summarised in Fig. 1.

\subsection{BIM's potential for KM}

On the basis of the analysis results of the interview, BIM has three potential aspects for KM, namely, knowledge capture and retention, proactive KM and visualisation-supported KM. BIM allows users to add data related to building objects in the model, such as materials and size. Meanwhile, users can create custom parameters in the BIM model, which can be used to capture and retain knowledge. For example, customised parameters are used to record the knowledge in the BIM model and to instruct the contractors on how to install or construct a specific object in a building. Such customised parameters can also retain knowledge to guide the FM team on how to operate/maintain the facilities during the O\&M stage. The method of capturing and retaining knowledge by using the customised parameters in the BIM model has also been indicated in previous studies, such as Motawa and Almarshad (2013) and Deshpande et al. (2014). Interviewees also suggested that client/end users should indicate the information and knowledge that they need. Then, the design team and contractors input the needed 


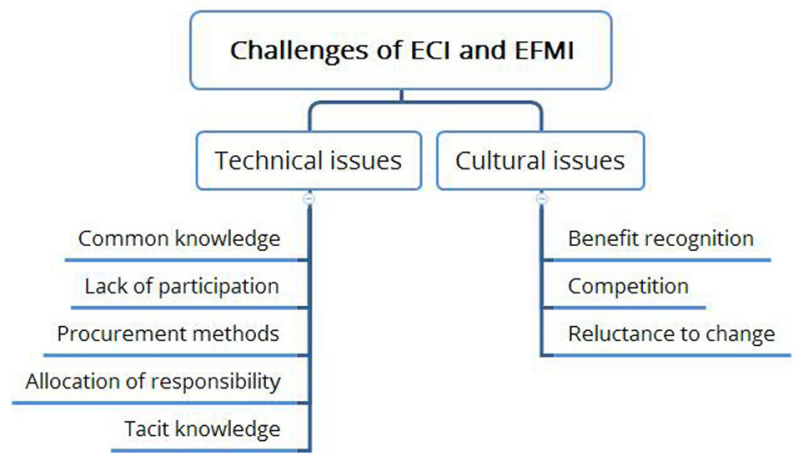

Fig. 1 Challenges of ECI and EFMI identified by the interviewees

information and knowledge in the BIM model. This information and knowledge-rich model will be delivered to the FM team for O\&M tasks. However, at present, client/end users are only encouraged to indicate the information that they need in the BIM model rather than knowledge.

Interviewees also indicate that the visualisation of BIM can also help the KM, particularly for the knowledge sharing between different disciplinary teams. Some interviewees explain that some project teams, such as FM team and client, lacked geometric thinking and design knowledge. They can hardly communicate their ideas with other disciplinary teams. If $3 \mathrm{D}$ visualisation provides support, then the FM people and client/end users can easily understand the design intention. They can also easily know if the design meets the O\&M requirements, building functions and business objectives. Consequently, they can provide their advices to improve the design. For example, doctors and nurses can use $3 \mathrm{D}$ visualisation as a basis to suggest to the design team what the layout of the operation room should be and the space planned to transport equipment. The studies of Luck (2007) and Ewenstein and Whyte (2009) supported this interview finding. Ewenstein and Whyte (2009) stressed that visual representations can be used to manipulate epistemic objects that enable different epistemic communities to work in a shared way. Consequently, the issues can be solved based on a mutual understanding. According to Luck (2007), the level of clients' understanding on the design can be improved in the conversations with the support of artefacts, such as drawings and models. The knowledge can also be embedded in the artefacts themselves. Accordingly, the 3D visualisation of BIM in this study can be regarded as a form of artefacts.

The interviewees also stressed that BIM can facilitate a proactive KM. A possible motivation for this is mainly based on the detection, simulation and early estimation functions of BIM. Supported by these functions, the design teams can proactively find the potential problems and apply their knowledge and experience to solve them in advance. The simulation function of BIM also facilitates the lifecycle issues to be discussed early in the design stage, such as lifecycle cost, energy consumption and maintenance space requirement. Consequently, project teams can make an informed decision in the early design stage based on their knowledge and experience.

\subsection{Expectations of BIM-based KM for ECI and EFMI}

The interviewees suggested that the BIM-based knowledge-sharing platform should enable people to comment on the related building objects of BIM. In addition, they believe that a discussion module should be included in the BIM-based KM to facilitate interaction during knowledge sharing. The interviewees even think that embedding a common data environment (CDE) to BIM-based KM is necessary. This opinion is likely due to the fact that CDE as a central repository includes project-related documentation and graphical and non-graphical data. Although CDE is currently applied exclusively to the information level, such an environment can also be theoretically applied to the knowledge level. Consequently, project parties can share and acquire knowledge on a central platform and avoid errors and conflicts caused by the inconsistency and dispersion of knowledge. Moreover, storing knowledge in the central repository provided by CDE can alleviate the problem of knowledge redundancy in a BIM-based KM system. The expectations of knowledge sharing mentioned in the interviews are all about explicit knowledge. Although the interviewees understand the importance of tacit knowledge, they did not propose any relevant strategies to manage tacit knowledge in this system.

The interviewees also expect that the BIM-based KM can be used to capture and retain knowledge. The possible reason is that the customised parameters of BIM enable users to add a descriptive natural language. Thus, the customised parameters of BIM enable people to add knowledge related to building objects or even projects. Although BIM can be regarded as a single central repository to capture and retain knowledge, interviewees believe that the reliability of importing knowledge from the BIM model into the external database can improve management. The interviewees also reiterated that during the process of knowledge retention, a common 'language' should be used for the knowledge index because this BIM-based KM system is intended for the collaboration of different disciplines in the design stage. The interviewees also explained that with the increasing 
knowledge in the proposed system, the problem of redundancy should be avoided. The interviewees suggested two solutions. One solution is to generalise knowledge, and the other solution is to update the previous knowledge based on the latest problems. One interviewee explained that he expected that this system can enable knowledge transfer from the project level to organisational level.

The interviewees listed three expected methods of knowledge presentation. The first method is to present knowledge in case studies, in which the background information of previous knowledge can be considered when people reuse the knowledge for a current problem. The second method is to link knowledge with related building objects in the BIM model, by which the visualisation of BIM can be used to obtain an improved understanding of the knowledge. The third method involves using conversation as a knowledge presentation method during the knowledge exchange, because this technique can facilitate the evaluation of the reliability of knowledge and inspire new ideas.

The expectation of knowledge reuse is mainly about knowledge retrieval. The interviewees proposed three available methods of knowledge retrieval, namely, keywords, condition-based filter and category-based retrieval. In addition, the interviewees suggested that the BIM-based KM system should consider how to revise the retrieved previous solutions to adapt to the situation of current situation. Although previous studies have explored how to identify the previous solutions to address the problems, such as the CBR applied in the study of (Motawa and Almarshad, 2013), the knowledge adaptation process still mainly relies on people. This adaptation process is labour intensive. The proposed BIM-based KM system should pay attention to the automatic knowledge adaptation process.

Furthermore, it is proposed that checking systems of specific domain rules and rule-based reasoning (RBR) can be integrated with BIM systems to support the knowledge adaptation process. Automatic knowledge adaptation approaches are not given in the original CBR cycle proposed by Aamodt and Plaza (1994). In Fig. 2, an RBR mechanism is added to the original CBR cycle to aid knowledge adaptation.

Interviewees also pointed out that the proposed BIMbased KM system should be applied in an appropriate process. They indicated three project management strategies that can be used to regulate the use of BIM. The three project management strategies are asset information requirement (AIR), explorer's information requirement
(EIR) and soft landing (SL). Air is used to specify the information required from an organisation in relation to an asset. EIR is developed based on AIR, in which the information required by a client for project development and operation should be specified. In addition, the information provided in EIR will facilitate decision making at each employer's decision point. SL is a strategy that stresses collaboration among the design, construction and O\&M phases. This process includes a post-project evaluation that can provide the lessons learned for future projects. Therefore, SL can facilitate knowledge reuse. Although the three project management strategies are currently applied at the information level, if BIM-based $\mathrm{KM}$ is integrated to these project management strategies or regard AIR, EIR and SL as knowledge carriers, then the collaborative KM can be improved.

\subsection{BIM-based KM framework for ECI and EFMI}

Based on the results of interviews and literature review, the requirements of ECI and EFMI in the BIM environment should be classified into three aspects, namely, technical, process and cultural. Table 3 shows the details of these requirements. Table 3 also lists the number of interviewees that mentioned a specific requirement and the number of times each requirement is mentioned by the 30 interviewees. Technical aspect includes the three traditional KM activities, namely, knowledge capture and retention, sharing and reuse, and also the other six aspects of technical requirements that mainly focus on the improvement

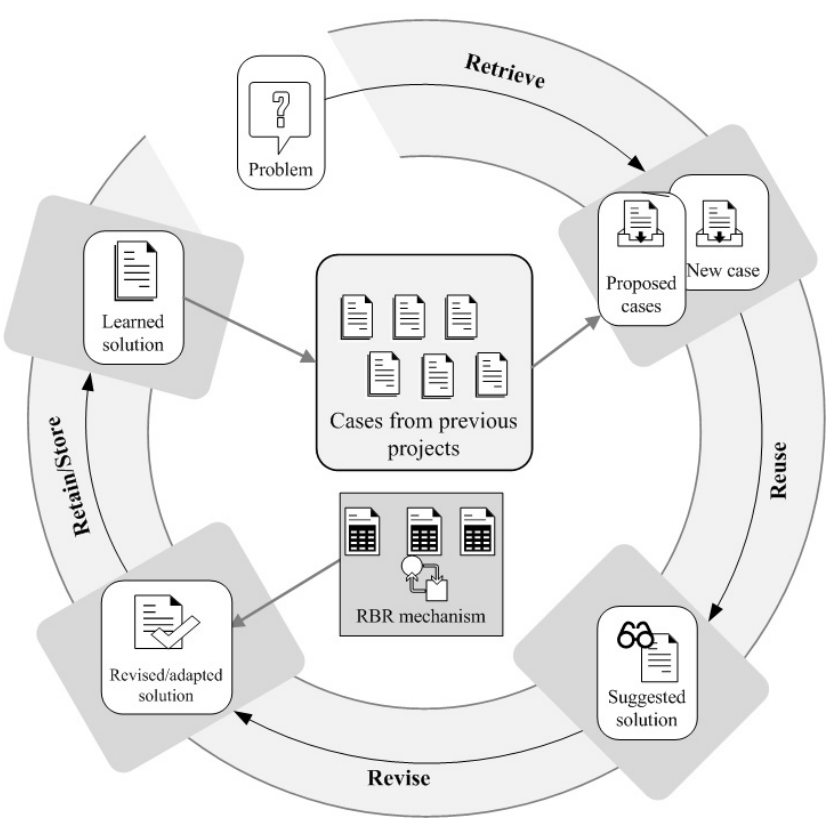

Fig. 2 CBR cycle with RBR mechanism for knowledge adaptation 
Table 3 Details of the requirements of BIM-based KM system

\begin{tabular}{|c|c|c|}
\hline Requirements of BIM-based KM & $\begin{array}{c}\text { Number of times mentioned by } \\
\text { the interviewees }\end{array}$ & Number of quotes \\
\hline \multicolumn{3}{|l|}{ Technical } \\
\hline Knowledge sharing & 21 & 66 \\
\hline Knowledge capture and retain & 7 & 10 \\
\hline Knowledge reuse (retrieval and adaptation) & 15 & 43 \\
\hline Tacit knowledge & 5 & 12 \\
\hline Proactive KM & 21 & 57 \\
\hline Common knowledge & 7 & 9 \\
\hline Responsibility allocation & 5 & 8 \\
\hline Knowledge presentation & 22 & 44 \\
\hline \multicolumn{3}{|l|}{ Process } \\
\hline AIR & 9 & 10 \\
\hline EIR & 16 & 29 \\
\hline SL & 5 & 14 \\
\hline From project to organisation & 1 & 1 \\
\hline Strategies for lack of participation & 2 & 3 \\
\hline \multicolumn{3}{|l|}{ Cultural } \\
\hline Relief of conflicts & 3 & 3 \\
\hline Adaptation to change & 12 & 12 \\
\hline Understanding of benefits & 10 & 14 \\
\hline
\end{tabular}

of early collaboration. The six additional technical aspects are management of tacit knowledge, improvement of common understanding, proactive KM, knowledge adaptation, knowledge presentation and responsibility allocation.

The process aspect mainly considers the combination of AIR, EIR and SL with BIM-based KM. To overcome the loss of knowledge, the process aspect also needs to solve the problem of lack of participation in KM activities at the end of a project. In addition, the proposed BIM-based KM system needs to consider how to transfer knowledge from temporary projects to a permanent part of an organisation.

The requirements of cultural aspect are mainly based on the literature review. These requirements were generated in response to the barriers of ECI and EFMI that are founded in the preview studies. Firstly, a construction project should establish a 'win-win' environment, which requires mutual understanding, adaptability to change of new work routes and understanding the benefits of early collaboration.

The three aspects of the proposed BIM-based KM system for ECI and EFMI are not independent but complementary. Fig. 3 illustrates the relationship between the three aspects and BIM's potential for KM.

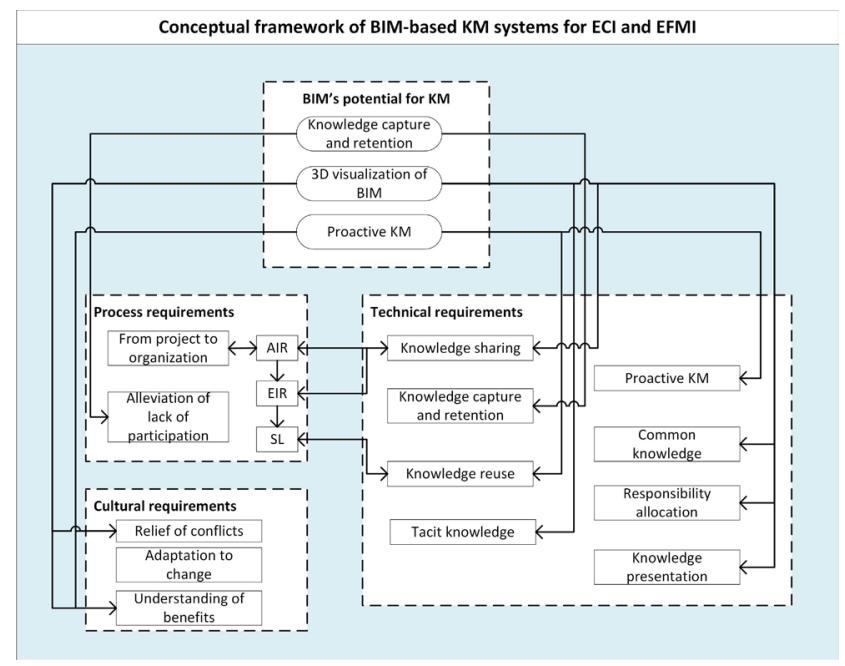

Fig. 3 Proposed BIM-based KM framework for ECI and EFMI

\section{Conclusion}

Semi-structured interviews are selected as the main method to explore how the knowledge of construction contractors and FM teams can be involved in the design stage with the help of BIM technology. The current strategies of ECI and EFMI are initially explored. Then, BIM's potential for KM is identified. On the basis of the interview 
results, BIM's potential for KM includes parametric modelling-based knowledge capture and retention, 3D visualisation-aided $\mathrm{KM}$ and simulation and analysis-supported proactive KM. This study also revealed the expectations of BIM-based KM for ECI and EFMI. A conceptual BIMbased KM system for early collaboration in the design stage was also developed.

This study only explored the KM in the BIM environment based on the results of the qualitative research (semi-structured interview). Future research should consider applying quantitative research methods to confirm the findings of this study and quantifying the impact of BIM on KM. In addition, future research should try to

\section{References}

Aamodt, A., Plaza, E. (1994) "Case-based reasoning: Foundational issues, methodological variations, and system approaches", AI Communications, 7(1), pp. 39-59.

Anumba, C. J., Egbu, C., Carrillo, P. (2008) "Knowledge management in construction", John Wiley \& Sons, Hoboken.

Arditi, D., Elhassan, A., Toklu, Y. C. (2002) "Constructability analysis in the design firm", Journal of Construction Engineering and Management, 128(2), pp. 117-126.

https://doi.org/10.1061/(ASCE)0733-9364(2002)128:2(117)

Bröchner, J. (2003) "Integrated development of facilities design and services", Journal of Performance of Constructed Facilities, 17(1), pp. 19-23.

https://doi.org/10.1061/(ASCE)0887-3828(2003)17:1(19)

Carrillo, P., Robinson, H. S., Al-Ghassani, A. M., Anumba, C. J. (2004) "Knowledge management in UK construction: Strategies, resources and barriers", Project Management Journal, 25(1), pp. 46-56.

Charlesraj, V. P. C. (2014) "Knowledge-based building information modeling (K-BIM) for facilities management", In: Proceedings of the 31st International Symposium on Automation and Robotics in Construction and Mining (ISARC). Sydney, Australia, pp. 936-941. https://doi.org/10.22260/ISARC2014/0127

Chi, N.-W., Lin, K.-Y., Hsieh, S.-H. (2014) "Using ontology-based text classification to assist job hazard analysis", Advanced Engineering Informatics, 28(4), pp. 381-394. https://doi.org/10.1016/j.aei.2014.05.001

Dave, B., Koskela, L. (2009) "Collaborative knowledge management-a construction case study", Automation in Construction, 18(7), pp. 894-902. https://doi.org/10.1016/j.autcon.2009.03.015

Deshpande, A., Azhar, S., Amireddy, S. (2014) "A framework for a BIMbased knowledge management system", Procedia Engineering, 85, pp. 113-122.

https://doi.org/10.1016/j.proeng.2014.10.535

Ding, L. Y., Zhong, B. T., Wu, S., Luo, H. B. (2016) "Construction risk knowledge management in BIM using ontology and semantic web technology", Safety Science, 87, pp. 202-213.

https://doi.org/10.1016/j.ssci.2016.04.008 develop a prototype model to evaluate the research results of this study and to obtain feedback from the industry.

This study also provides BIM-related research an idea that transforms BIM into building knowledge modelling.

\section{Acknowledgement}

This research was supported by the China Scholarship Council (Grant Number 201508520030). The authors also wish to express their gratitude for the support received from the School of Natural and Built Environment and the Sustainable Built Environment Research Cluster at Queen's University Belfast. The authors also wish to thank all interview participants for their valuable contributions to this study.

Dretske, F. I. (1983) "Precis of knowledge and the flow of information", Behavioral and Brain Sciences, 6(1), pp. 55-63. https://doi.org/10.1017/S0140525X00014631

Dunston, P. S., Williamson, C. E. (1999) "Incorporating maintainability in constructability review process", Journal of Management in Engineering, 15(5), pp. 56-60. https://doi.org/10.1061/(ASCE)0742-597X(1999)15:5(56)

Eadie, R., Millar, P., Mahon, C., Ferguson, M. (2012) "The feasibility and rationale for using early contractor involvement ECI in Northern Ireland", In: Proceedings of the 7th International Conference on Innovation in Architecture, Engineering and Construction (AEC), The Brazilian British Centre, São Paulo, Brazil.

Eastman, C. M., Eastman, C., Teicholz, P., Sacks, R. (2011) "BIM handbook: A guide to building information modeling for owners, managers, designers, engineers and contractors", John Wiley \& Sons, Hoboken, New Jersey, USA.

Ewenstein, B., Whyte, J. (2009) "Knowledge practices in design: The role of visual representations as 'epistemic objects'", Organization Studies, 30(1), pp. 07-30. https://doi.org/10.1177/0170840608083014

Fong, P. S., Wong, K.-C. (2009) "Knowledge and experience sharing in projects-based building maintenance community of practice", International Journal of Knowledge Management Studies, 3(3-4), pp. $275-294$. https://doi.org/10.1504/ijkms.2009.028841

Fruchter, R., Schrotenboer, T., Luth, G. P. (2009) "From building information model to building knowledge model", In: Computing in Civil Engineering 2009, Austin, Texas, pp. 380-389. https://doi.org/10.1061/41052(346)38

Gil, N., Tommelein, I., Kirkendall, R., Ballard, G. (2000) "Contribution of specialty contractor knowledge to early design", In: Proceedings of the Eighth Annual Conference of the International Group for Lean Construction, Brighton, UK.

Gil, N., Tommelein, I., Kirkendall, R., Ballard, G. (2001) "Leveraging specialty-contractor knowledge in design-build organizations", Engineering Construction and Architectural Management, 8(5-6), pp. 355-367. https://doi.org/10.1108/eb021196 
Gómez-Romero, J., Bobillo, F., Ros, M., Molina-Solana, M., Ruiz, M. D., Martín-Bautista, M. J. (2015) "A fuzzy extension of the semantic building information model", Automation in Construction, 57, pp. 202-212.

https://doi.org/10.1016/j.autcon.2015.04.007

Grover, R., Froese, T. M. (2016) "Knowledge management in construction using a socioBIM platform: A case study of ayo smart home projec", Procedia Engineering, 145, pp. 1283-1290.

https://doi.org/10.1016/j.proeng.2016.04.165

Hari, S., Egbu, C., Kumar, B. (2005) "A knowledge capture awareness tool: An empirical study on small and medium enterprises in the construction industry", Engineering, Construction and Architectural Management, 12(6), pp. 533-567. https://doi.org/10.1108/09699980510634128

Ho, S.-P., Tserng, H.-P., Jan, S.-H. (2013) "Enhancing knowledge sharing management using BIM technology in construction", The Scientific World Journal, 2013. https://doi.org/10.1155/2013/170498

Jan, S.-H., Ho, S.-P., Tserng, H.-P. (2013) "Applications of building information modeling (BIM) in knowledge sharing and management in construction", International Journal of Civil and Environmental Engineering, 7(11), pp. 828-832.

Jensen, P. A. (2009) "Design integration of facilities management: A challenge of knowledge transfer", Architectural Engineering and Design Management, 5(3), pp. 124-135. https://doi.org/10.3763/aedm.2009.0101

Jergeas, G., Van der Put, J. (2001) "Benefits of constructability on construction projects", Journal of Construction Engineering and Management, 127(4), pp. 281-290. https://doi.org/10.1061/(ASCE)0733-9364(2001)127:4(281)

Kadefors, A. (2004) "Trust in project relationships - inside the black box", International Journal of Project Management, 22(3), pp. 175-182. https://doi.org/10.1016/S0263-7863(03)00031-0

Kamara, J. M., Augenbroe, G., Anumba, C. J., Carrillo, P. M. (2002) "Knowledge management in the architecture, engineering and construction industry", Construction Innovation, 2(1), pp. 53-67. https://doi.org/10.1108/14714170210814685

Kim, H., Grobler, F. (2009) "Design coordination in building information modeling (BIM) using ontological consistency checking", International Workshop on Computing in Civil Engineering 2009, Austin, Texas, USA, pp. 410-420. https://doi.org/10.1061/41052(346)41

Kivits, R. A., Furneaux, C. (2013) "BIM: Enabling sustainability and asset management through knowledge management", The Scientific World Journal, 2013. https://doi.org/10.1155/2013/983721

Kivrak, S., Arslan, G., Dikmen, I., Birgonul, M. T. (2008) "Capturing knowledge in construction projects: Knowledge platform for contractors", Journal of Management in Engineering, 24(2), pp. 87-95. https://doi.org/10.1061/(asce)0742-597x(2008)24:2(87)

Konukcu, S., Koseoglu, O. (2012) "Knowledge management through BIM in construction supply chains", In: Proceedings of the CIB W78 2012: 29th International Conference, Beirut, Lebanon, pp. $448-457$.
Le, Q. T., Lee, D. Y., Park, C. S. (2014) "A social network system for sharing construction safety and health knowledge", Automation in Construction, 46, pp. 30-37. https://doi.org/10.1016/j.autcon.2014.01.001

Lee, J. R., Hsueh, S. L., Tseng, H. P. (2008) "Utilizing data mining to discover knowledge in construction enterprise performance records", Journal of Civil Engineering and Management, 14(2), pp. 79-84. https://doi.org/10.3846/1392-3730.2008.14.2

Lin, Y.-C. (2014) "Construction 3d BIM-based knowledge management system: A case study", Journal of Civil Engineering and Management, 20(2), pp. 186-200. https://doi.org/10.3846/13923730.2013.801887

Lin, Y.-C., Lee, H.-Y. (2012) "Developing project communities of practice-based knowledge management system in construction", Automation in Construction, 22, pp. 422-432. https://doi.org/10.1016/j.autcon.2011.10.004

Lin, Y.-C., Wang, L.-C., Tserng, H. P. (2006) "Enhancing knowledge exchange through web map-based knowledge management system in construction: Lessons learned in taiwan", Automation in Construction, 15(6), pp. 693-705. https://doi.org/10.1016/j.autcon.2005.09.006

Liu, F., Jallow, A. K., Anumba, C. J., Wu, D. (2013) "Building knowledge modeling: Integrating knowledge in BIM", In: Proceedings of the CIB W78 2013: 30th International Conference, Beijing, China, pp. 199-208.

Liu, R., Issa, R. R. A. (2012). "Automatically updating maintenance information from a BIM database", In: International Conference on Computing in Civil Engineering, Clearwater Beach, Florida, United States, pp. 373-380. https://doi.org/10.1061/9780784412343.0047

Love, P. E. D., Damien, O. D., Davis, P. R., Smith, J. (2014) "Procurement of public sector facilities: Views of early contractor involvement", Facilities, 32(9/10), pp. 460-471. https://doi.org/10.1108/F-03-2012-0020

Luck, R. (2007) "Using artefacts to mediate understanding in design conversations", Building Research, Information, 35(1), pp. 28-41. https://doi.org/10.1080/09613210600879949

Meadati, P., Irizarry, J. (2010) "BIM-a knowledge repository", In: Proceedings of the 46th Annual International Conference of the Associated Schools of Construction, Boston, Massachusetts, USA.

Meng, X. (2013) "Involvement of facilities management specialists in building design: United Kingdom experience", Journal of Performance of Constructed Facilities, 27(5), pp. 500-507. https://doi.org/10.1061/(ASCE)CF.1943-5509.0000343

Meng, X. (2014) "Is early warning effective for the improvement of problem solving and project performance?", Journal of Management in Engineering, 30(2), pp. 146-152. https://doi.org/10.1061/(ASCE)ME.1943-5479.0000205

Mohammed, M. A., Hassanain, M. A. (2010) "Towards improvement in facilities operation and maintenance through feedback to the design team", The Built \& Human Environment Review, 3, pp. 72-87.

Motamedi, A., Hammad, A., Asen, Y. (2014) "Knowledge-assisted BIMbased visual analytics for failure root cause detection in facilities management", Automation in Construction, 43, pp. 73-83. https://doi.org/10.1016/j.autcon.2014.03.012 
Motawa, I., Almarshad, A. (2013) "A knowledge-based BIM, system for building maintenance", Automation in Construction, 29, pp. $173-182$. https://doi.org/10.1016/j.autcon.2012.09.008

Motawa, I., Almarshad, A. (2015) "Case-based reasoning and BIM systems for asset management", Built Environment Project and Asset Management, 5(3), pp. 233-247. https://doi.org/10.1108/BEPAM-02-2014-0006

Motawa, I., Janarthanam, S., Almarshad, A. (2014) "Live capture of energy-related knowledge into BIM systems", In: Construction Research Congress, Atlanta, Georgia, pp. 249-258. https://doi.org/10.1061/9780784413517.026

Motiar, R., Aminu, A. (2012) "A contractor's perception on early contractor involvement", Built Environment Project and Asset Management, 2(2), pp. 217-233. https://doi.org/10.1108/20441241211280855

Nguyen, T. H., Toroghi, S. H. (2013) "Knowledge representation in BIM for evaluating sustainability of a building design", In: the New Developments in Structural Engineering and Construction, Manoa, Honolulu, USA.

https://doi.org/10.3850/978-981-07-5354-2_AAE-12-238

Ofek, E., Sarvary, M. (2002) "Leveraging the customer base: Creating competitive advantage through knowledge management", Management Science, 47(11), pp. 1441-1456. https://doi.org/10.2139/ssrn.310880

Park, C.-S., Lee, D.-Y., Kwon, O.-S., Wang, X. (2013a) "A framework for proactive construction defect management using BIM, augmented reality and ontology-based data collection template", Automation in Construction, 33, pp. 61-71. https://doi.org/10.1016/j.autcon.2012.09.010

Park, M., Lee, K.-W., Lee, H.-S., Jiayi, P., Yu, J. (2013b) "Ontology-based construction knowledge retrieval system", KSCE Journal of Civil Engineering, 17(7), pp. 1654-1663. https://doi.org/10.1007/s12205-013-1155-6

Patton, M. Q. (1990) "Qualitative evaluation and research methods", SAGE Publications, INC, Thousand, London, New Delhi.

Prencipe, A., Tell, F. (2001) "Inter-project learning: Processes and outcomes of knowledge codification in project-based firms", Research policy, 30(9), pp. 1373-1394. https://doi.org/10.1016/s0048-7333(01)00157-3

Quigley, E. J., Debons, A. (1999) "Interrogative theory of information and knowledge", In: Proceedings of the 1999 ACM SIGCPR conference on Computer personnel research, New Orleans, Louisiana, USA, pp. 4-10. https://doi.org/10.1145/299513.299602

Samuel, L., Ron, W. (2016) "Early contractor involvement in framework contracts", Proceedings of the Institution of Civil Engineers Management, Procurement and Law, 169(1), pp. 4-16. https://doi.org/10.1680/jmapl.15.00012
Soibelman, L., Liu, L. Y., Kirby, J. G., East, E. W., Caldas, C. H., Lin, K.-Y. (2003) "Design review checking system with corporate lessons learned", Journal of Construction Engineering and Management, 129(5), pp. 475-484. https://doi.org/10.1061/(asce)0733-9364(2003)129:5(475)

Song, L., Mohamed, Y., Abourizk, S. M. (2009) "Early contractor involvement in design and its impact on construction schedule performance", Journal of Management in Engineering, 25(1), pp. 12-20. https://doi.org/10.1061/(ASCE)0742-597X(2009)25:1(12)

Sydow, J., Lindkvist, L., Defillippi, R. (2004) "Project-based organizations, embeddedness and repositories of knowledge", Organization Studies, 25(9), pp. 1475-1489. https://doi.org/10.1177/0170840604048162

Tserng, H. P., Yin, S. Y., Dzeng, R., Wou, B., Tsai, M., Chen, W. (2009) "A study of ontology-based risk management framework of construction projects through project life cycle", Automation in Construction, 18(7), pp. 994-1008. https://doi.org/10.1016/j.autcon.2009.05.005

Udeaja, C. E., Kamara, J. M., Carrillo, P. M., Anumba, C. J., Bouchlaghem, N., Tan, H. C. (2008) "A web-based prototype for live capture and reuse of construction project knowledge", Automation in Construction, 17(7), pp. 839-851. https://doi.org/10.1016/j.autcon.2008.02.009

Ur-Rahman, N., Harding, J. A. (2012) "Textual data mining for industrial knowledge management and text classification: A business oriented approach", Expert Systems with Applications, 39(5), pp. $4729-4739$.

https://doi.org/10.1016/j.eswa.2011.09.124

Van Valkenburg, M., Lenferink, S., Nijsten, R., Arts, J. (2008) "Early contractor involvement: A new strategy for "buying the best" in infrastructure development in the netherlands", In: Third International Public Procurement Conference (IPPC), Amsterdam, Netherlands. pp. 323-356.

Wang, H., Meng, X., McGetrick, P. J. (2018) "Involving knowledge of construction and facilities management in design through the BIM approach", In: Proceedings of the Creative Construction Conference 2018, Ljubljana, Slovenia.

Wang, L., Leite, F. (2016) "Process knowledge capture in BIM-based mechanical, electrical, and plumbing design coordination meetings", Journal of Computing in Civil Engineering, 30(2), pp. 04015017.

https://doi.org/10.1061/(ASCE)CP.1943-5487.0000484

Wang, Y., Wang, X., Wang, J., Yung, P., Jun, G. (2013) "Engagement of facilities management in design stage through BIM: Framework and a case study", Advances in Civil Engineering, 2013. https://doi.org/10.1155/2013/189105 